profound harmony between the theoretical and experimental practice of Ampère, Faraday, F. Neumann, W. Weber, Kelvin, Maxwell, Helmholtz and Hertz.

Darrigol's guided tour of the "lofty summits of the history of electrodynamics" will appeal to historians and philosophers of science, as well as to physicists, mathematicians, and engineers interested in the origins and evolution of field theory. Regardless of how one may feel about the chances for success of non-Maxwellian alternatives a century ago, Darrigol's informed analysis of the evolution of electromagnetic theory and experiment effectively illustrates the subtle ways by which Maxwell's equations came to shape visions of the future. Scott Walter is in the Department of Philosophy, Archives Henri Poincaré, Université Nancy 2, 23 Bd Albert 1er, 54015 Nancy Cédex, France.

\section{Not so crazy after all}

\section{Strong Imagination: Madness,} Creativity and Human Nature by Daniel Nettle

Oxford University Press: 2001. 192 pp. $£ 16.99$

\section{Dylan Evans}

"I have long had a suspicion," wrote the great Victorian psychiatrist Henry Maudsley in 1871, "that mankind is indebted for much of its individuality and for certain forms of genius to individuals [with] some predisposition to insanity. They have often taken up the by-paths of thought, which have been overlooked by more stable intellects." In Strong Imagination, Daniel Nettle takes up Maudsley's suspicion and runs with it. He argues that the genes that predispose people to schizophrenia and manic depression have been maintained in the gene pool by natural selection because of their beneficial effects in enhancing creativity.

The idea that madness and creative genius are but two sides of the same coin has a long and distinguished pedigree, originating long before Maudsley. In the past few decades, the idea has been subjected to ingenious statistical tests by Kay Redfield Jamison, Arnold Ludwig, Nancy Andreasen, Felix Post and others. Nettle reviews this literature, and suggests a couple of reasons why a little dose of madness might be a good thing for a creative artist; mania provides the energy and drive necessary for sustained lonely work, and schizotypy favours divergent thinking. Add to this the idea that creativity leads to greater reproductive success, and the result is an adaptationist account of schizophrenia. The account is adaptationist, not because it requires that schizophrenics have more babies - Nettle rightly draws back from this claim - but because it implies that the genes that predispose towards schizo-

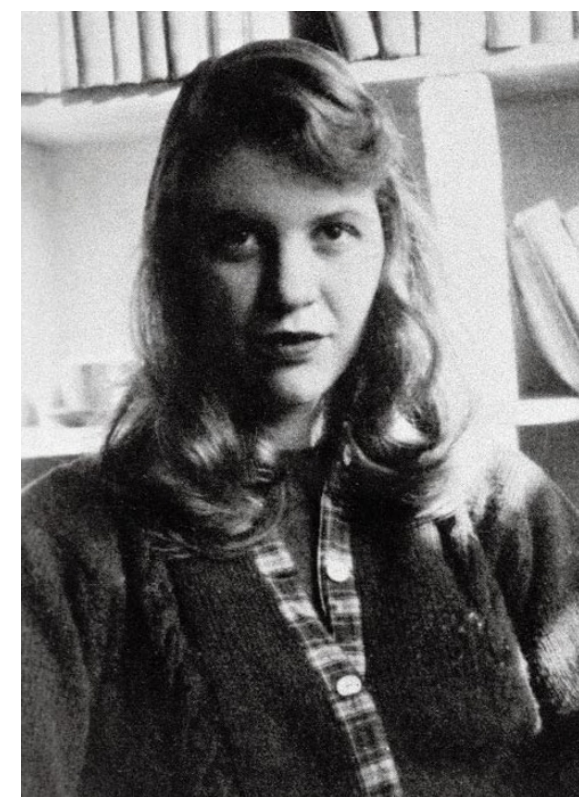

Sylvia Plath: creative and depressed — but why?

phrenia have remained in the gene pool because they also enhance creativity.

From the chatty style, and the fact that even such basic biological entities as neurotransmitters and recessive genes are explained in simple terms, it is clear that the book is aimed at the general reader with very little knowledge of psychiatry or evolutionary theory. Such readers will no doubt learn a lot from the book, as it covers an impressive range of material, from the history of ideas about mental illness in the twentieth century and the basic principles of neurochemistry, to the phenomenology of psychosis and the theory of sexual selection. They may even find themselves persuaded by Nettle's thesis. Those already familiar with the literature, however, will find the book less convincing.

Nettle frequently claims to have "argued" for some claim or even "demonstrated" it, when in fact he has merely proposed or assumed it. The result is a text that may please the converted but will not persuade the sceptic. This is perhaps most obvious when Nettle discusses the supposed evolutionary advantages for psychological traits such as low/high mood and creative flair. "How," he asks at one point, "can low mood be adaptive, given that in all primate groups, status is positively related to reproductive success, and low mood makes us drop in status?" One obvious answer is that low mood might not be adaptive at all, but Nettle doesn't even consider this possibility. This is just the kind of approach that has got adaptationism a bad name, and which more cautious adaptationists such as George Williams have repeatedly criticized.

Nettle's grasp of evolutionary theory is much weaker than his grasp of psychiatry, which is generally sound. Reflecting this imbalance, the citation of authorities is also very uneven: in the chapters about psychosis all the usual suspects are there, but when it comes to evolutionary psychology we find a very skewed sample. On the one hand, the major figures in the field are notable by their absence. The Machiavellian intelligence hypothesis is discussed (although not named), but there is no mention of Nicholas Humphrey, who first proposed it, and Robin Dunbar, who has done much to test this hypothesis, only gets a brief nod in the acknowledgements (Richard Byrne and Andrew Whiten don't even get that). Likewise, Nettle advances something suspiciously like Randolph Nesse's propitiousness hypothesis of mood without mentioning Nesse's name at all.

On the other hand, the authorities who are mentioned are among the least trustworthy, and several ideas are misattributed. Nettle seems particularly impressed by Anthony Stevens and John Price, although their book, Evolutionary Psychiatry (Routledge), is among the more dubious contributions to the field, and he credits them with the idea that the modern world has changed too fast for the human mind, which is still adapted to the pleistocene. Now, Stevens and Price may well have baptized this hypothesis with a particularly catchy name - they call it the 'genome lag' hypothesis - but it is certainly not their invention. It is, in fact, one of the staple ideas in evolutionary psychology, and goes back at least as far as John Bowlby.

The one evolutionary psychologist who is both a major player in the field and cited frequently in the book is Geoffrey Miller. Miller's view that sexual selection has played a much greater role than natural selection in shaping the most distinctively human aspects of our minds is linked suggestively with the view that the genes for madness are also genes for creativity. Indeed, the main virtue of Nettle's book is that it brings these two hypotheses together in a single work for the first time. This is a task that needed to be done, and we must be grateful to Nettle for undertaking it.

Despite the occasional stylistic infelicity and the overuse of the first person singular, Nettle writes well. He enlivens the scientific data with fascinating clinical vignettes, anthropological observations, and wellchosen quotations from Shakespeare. The book may not contain anything strikingly new or original, but it does constitute a readable and up-to-date review of a very large body of literature on a fascinating subject. The lack of novelty may seem odd in a book about creativity, but perhaps this is no bad thing. If Nettle is right, novelty is often purchased at the price of delusion. It is reassuring, then, to read that one of the studies cited in the book shows that, out of a wide range of "eminent people", scientists had one of the lowest lifetime rates of mental disorder.

Dylan Evans is in the Department of Philosophy, King's College London, 160 The Strand, London WC2R 2LS, UK. 